\title{
Mechanically Induced Martensitic Transformation of Hot Rolled and Annealed 304L Austenitic Stainless Steel at Room and Cryogenic Temperatures
}

\author{
Juciane Maria Alves ${ }^{a} \mathbb{D}^{\mathbb{D}}$, Luiz Paulo Brandão ${ }^{a} \mathbb{D}^{\mathbb{D}}$, Andersan dos Santos Paula ${ }^{a} \mathbb{D}$ \\ ${ }^{a}$ Seção de Engenharia de Materiais, Instituto Militar de Engenharia, Rio de Janeiro, RJ, Brasil
}

Received: February 19, 2019; Revised: June 10, 2019; Accepted: July 27, 2019

\begin{abstract}
The 304L austenitic stainless steel is susceptible to mechanically induced martensitic transformation from slightly above room temperature down to cryogenic temperatures. In this work, austenitic 304L steel produced by two different thermomechanical processes, hot rolling (HR) and cold rolling and annealing (CR/A), were subjected to martensitic transformation by rolling and by tensile tests at $298 \mathrm{~K}$ and $155 \mathrm{~K}$ and the volume fraction of martensite was determined by X-ray diffraction and ferritescope measurements. The results showed that the martensitic transformation was complete for CR/A samples rolled at $155 \mathrm{~K}$ and that the volume fraction of martensite was larger in CR/A samples than in HR samples in all cases.
\end{abstract}

Keywords: 304L austenitic stainless steel, thermomechanical processing, martensitic transformation, cold rolling, tensile test.

\section{Introduction}

The martensitic transformation of austenitic stainless steels can occur in a wide range of temperatures and it is influenced by the deformation mode such as rolling and tensile test, among others. The product may be $\varepsilon$ or $\alpha^{\prime}$-martensite. Nucleation of $\varepsilon$-martensite, which has a hexagonal compact structure, occurs at the intersections of stacking faults while nucleation of $\alpha^{\prime}$-martensite, which has a body centered cubic structure, occurs from $\varepsilon$-martensite and at intersections of shear bands, under the influence of the stacking fault energy (SFE) of the austenite phase ${ }^{1-3}$. Growth of the $\alpha^{\prime}$-martensite occurs from the successive nucleation and coalescence of new nuclei. Consequently, new nuclei will be created as function of the new shear bands intersections ${ }^{4}$. The SFE depends on the chemical composition of the austenitic phase and on the process that induces the phase transformation and plays an important role in martensitic transformation. For instance, SFE values below $18 \mathrm{~mJ} \cdot \mathrm{m}^{-2}$ favor the transformation $\left(\gamma \rightarrow \varepsilon \rightarrow \alpha^{\prime}\right)^{1-2}$. The empirical Equations 1 and 2 can be used to calculate the SFE at room and other temperatures, respectively ${ }^{5}$ :

$$
\begin{gathered}
\mathrm{SFE}_{\mathrm{RT}}=-53+6.2(\% \mathrm{Ni})+0.7(\% \mathrm{Cr}) \\
+3.2(\% \mathrm{Mn})+9.3(\% \mathrm{Mo}) \mathrm{mJ} / \mathrm{m}^{2} \\
\mathrm{SFE}_{T}=\mathrm{SFE}_{\mathrm{RT}}+0.05(T-293) \mathrm{mJ} / \mathrm{m}^{2}
\end{gathered}
$$

Besides its influence on SFE, chemical composition of the alloy also influences important factors such as the starting temperature to martensite formation $\left(M_{s}\right)$, given by Equation 3. The $\mathrm{Md}_{30}$ temperature, Equation $4^{6-8}$, which is the temperature where $30 \%$ of the true strain imposed by stress induces a transformation of $50 \%$ of the austenite in martensite. Both the chemical composition and the induction temperature influence in the stability of austenite.
Less alloying elements additions and a lower induction temperature decrease the austenite stability, facilitating the martensitic transformation?

$$
\begin{gathered}
\mathrm{M}_{s}\left({ }^{\circ} \mathrm{C}\right)=1305-1665(\% \mathrm{C}+\% \mathrm{~N})-28(\% \mathrm{Si}) \\
-33(\% \mathrm{Mn})-42(\% \mathrm{Cr})-61(\% \mathrm{Ni}) \\
\mathrm{M}_{\mathrm{d} 30}\left({ }^{\circ} \mathrm{C}\right)=413-462(\% \mathrm{C}+\% \mathrm{~N})-9.2(\% \mathrm{Si}) \\
-8.1(\% \mathrm{Mn})-13.7(\% \mathrm{Cr})-9.5(\% \mathrm{Ni})-18.5(\% \mathrm{Mo})
\end{gathered}
$$

The transformation $\left(\gamma \rightarrow \alpha^{\prime}\right)$ in TRIP steel is strongly influenced by temperature. The plastic deformation increases the internal temperature of the material and, depending on the deformation rate, there may be no time to dissipate the heat, a phenomenon known as adiabatic heating. So, increasing the rate or amount of deformation to which the material is subjected increases its temperature. Depending on the intensity these effects, the phase transformation can be suppressed ${ }^{2,10-11}$. Low temperatures reduce adiabatic heating during deformation ${ }^{12}$.

In this work, austenitic 304L steel produced by two different thermomechanical processes, hot rolling (HR) and cold rolling and annealing (CR/A), were subjected to martensitic transformation by rolling and by tensile test at $298 \mathrm{~K}$ and $155 \mathrm{~K}$ and the volume fraction of martensite was determined by X-ray diffraction (XRD) and ferritescope measurements. It was obtained $100 \%$ martensitic samples for the $\mathrm{CR} / \mathrm{A}$ material after 60 and $80 \%$ reductions in cryogenic rolling at $155 \mathrm{~K}$, temperature estimated from the material chemical composition. The induced martensitic transformation by rolling was more intense than that induced by tensile test for the same equivalent deformations, the samples showed martensite volume fraction variation between surface and half thickness. 


\section{Experimental Procedure}

The raw material for this study consisted of 304L austenitic stainless steel sheets produced by two different processes: hot rolling $(\mathrm{HR})$ and cold rolling/annealing (CR/A) with thicknesses of 6.37 and $3.0 \mathrm{~mm}$, respectively. The chemical composition of the sheets is shown in Table 1.

The induced martensitic transformation by rolling in the HR material and the results were compared to those obtained by uniaxial tensile test in both HR and CR/A samples. The experiments were performed at two different temperatures, 298 $\mathrm{K}$ (room temperature) and $155 \mathrm{~K}$ (cryogenic temperature). The cryogenic temperature was chosen using Equation 3, which gives the starting temperature $M_{s}$ temperature as a function of the material chemical composition. Before the cryogenic tests, the samples were supercooled in liquid nitrogen for approximately 3 minutes. FENN MFG Co rolling mill, model D-51710:1973 with double configuration, conventional cylinders with a diameter of $133.70 \mathrm{~mm}$ was used to roll the steel sheets at room and cryogenic temperatures. The applying rolling reductions were $20,40,60$ and $80 \%$, with strain rate of $9.8 \times 10\left(\mathrm{~s}^{-1}\right) \pm 1.6$ and $5.4 \times 10\left(\mathrm{~s}^{-1}\right) \pm 0.66$ for room and cryogenic temperatures, respectively. The initial samples dimensions were $6 \mathrm{~cm}$ length and $4 \mathrm{~cm}$ width. Tensile deformations were applied up to 24 and $47 \%$, which is quite similar to the effective strain of 20 and $40 \%$ in rolling, corresponding to nominal strain rate of $2 \times 10^{-2}\left(\mathrm{~s}^{-1}\right)$. Test specimen dimensions were $100 \mathrm{~mm}$ total length, $25 \mathrm{~mm}$ useful length, $6 \mathrm{~mm}$ width and thicknesses of 6.37 and $3.0 \mathrm{~mm}$ for the hot rolled and cold rolled materials, respectively, all cut by laser. EMIC DL 60.000 with $100 \mathrm{kN}$ load cell was used for the room temperature tensile tests and the INSTRON 5500R with $150 \mathrm{kN}$ load cell was used for the cryogenic temperature tensile tests. For the cryogenic tests, the samples were initially supercooled in liquid nitrogen for approximately 3 minutes and the chamber was kept in the same temperature during the tests.
The metallographic preparation was performed with electrolytic polishing in perchloric acid solution (20\%) in ethanol, after sanding with grit of 1200 mesh. The polishing time of the samples in electrolytic solution was between 7 and 10 seconds, being smaller for larger martensite volumes. The voltage used in the equipment was $20 \mathrm{~V}$. In order to investigate the profile of the martensitic transformation, the thicknesses of two groups of samples were reduced by $3 / 4$ and $1 / 2$ by grinding the samples using 120, 220, 400, 600, 800 and 1200 grit papers.

The phase analyses were performed by XRD using a PANalytical X'PERT PRO MRD diffractometer with cobalt tube. The voltage and current were $40 \mathrm{kV}$ and $45 \mathrm{~mA}$, respectively. The measurement parameters were initial and final angles of 45 and $130^{\circ}$, a step size of $0.030^{\circ}$ and a time per step of $200 \mathrm{~s}$, which resulted in an acquisition time of 38 minutes. The phase quantification was performed by the Rietveld method, using TOPAS software version 5.2. The phase analyses by ferritescope measurements were performed using the ferritescope FISCHER_FMP30 with manual probe. The instrument was calibrated with ferrite standards. Thirty measurements were realized for each sample which produced an estimated standard deviation between 0.00 and 0.61 . Correction factors ${ }^{13}$ was used for thicknesses of less than or equal to $2 \mathrm{~mm}$. The average grain size was determined using a Scanning Electronic Microscope (SEM) FEG with an electron backscattered diffraction (EBSD) detector.

\section{Results and Discussion}

The results of induced martensitic transformation by rolling at room and cryogenic temperatures are shown in Figure 1. One can clearly see the increase of the intensity of the martensite diffraction peaks and the decrease of the austenite peaks as the deformation increases. The diffraction peaks associated with austenite and $\alpha^{\prime}$-martensite are, respectively, (111), (200), (220), (311), (222) and (110), (200), (211), (220).

Table 1. Chemical composition of 304L steel (weight \%).

\begin{tabular}{cccccccc}
\hline 304L Steel & $\mathrm{C}$ & $\mathrm{Mn}$ & $\mathrm{Si}$ & $\mathrm{Cr}$ & $\mathrm{Ni}$ & $\mathrm{Mo}$ & $\mathrm{N}$ \\
\hline $\mathrm{HR}$ & 0.0196 & 1.2617 & 0.4911 & 18.0363 & 8.0837 & 0.1351 & 0.0509 \\
$\mathrm{CR} / \mathrm{A}$ & 0.0196 & 1.2586 & 0.5729 & 18.0819 & 8.0045 & 0.1563 & 0.0422 \\
\hline
\end{tabular}
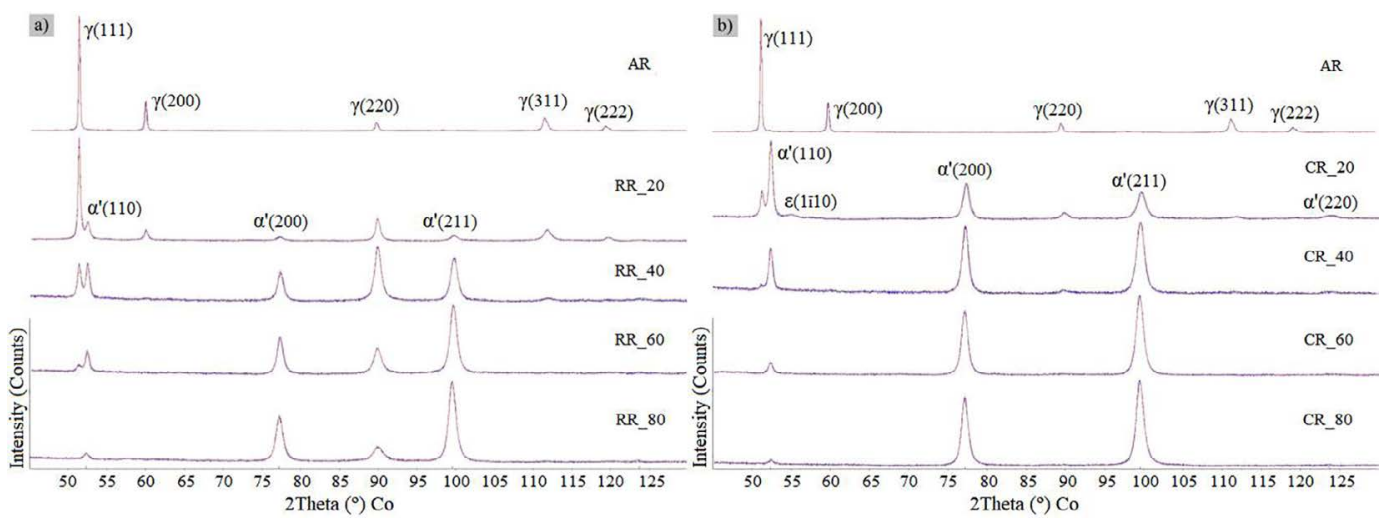

Figure 1. Diffractograms of rolled samples at $298 \mathrm{~K}$ (a) and $155 \mathrm{~K}$ (b) with reductions of 20, 40, 60 and $80 \%$. 
One can also see the presence of the (10111) plane of the $\varepsilon$-martensite for cryogenic rolling with $20 \%$ reduction. As shown in Figure 1(b), there was a 100\% martensitic transformation for reductions of 60 and $80 \%$ in cryogenic rolling. The SFE values, calculated using Equations (1) and (2), and the average grain sizes are shown in Table 2 for two different temperatures.

The depth profile of the martensitic transformation was determined comparing the diffractograms of whole samples with those of samples whose thickness was reduced by $3 / 4$ and $1 / 2$ of the original thickness, the results are shown in Figures 2 (a) and 2 (b). According to the results, the volume fraction of martensite is smaller inside the samples than near the surface and is larger in samples rolled at $155 \mathrm{~K}$ than in samples rolled at room temperature. XRD analysis performed on whole samples with $20 \%$ reduction showed $66 \%$ martensite and samples with $40 \%$ reduction was $98 \%$. For reductions of 60 and $80 \%$, a small increase was observed, approaching $100 \%$ martensite. The evolution of this phase transformation is clearly observed in the diffractograms shown in Figure 1 (b).
A high volume of martensite (96\%) was also observed in samples rolled at room temperature for a reduction of $80 \%$. According to the results of ferritescope measurements, shown in Figure 2 (b), the volume fraction of martensite was $80 \%$ for samples with 60 and $80 \%$ reductions in cryogenic rolling; this corresponds to the detection limit of ferromagnetic phase by ferritescope measurements for the equipment used in the measurements ${ }^{14}$. As reported by FISHER ${ }^{15}$, martensite nucleation occurs heterogeneously due to residual stress fields in the vicinity of the mismatches. Microstructural heterogeneity of this phase transformation is also reported by EGNER ${ }^{16}$. AMAR $^{12}$ and NAGY ${ }^{17}$ which observed that the volume fraction of martensite was a function of sample thickness.

The results of induced martensitic transformation by tensile test at room and cryogenic temperatures are shown in Figures 3 and 4. According to these results, the volume fraction of martensite induced by tensile test was much larger in samples rolled at $155 \mathrm{~K}$ than in samples rolled at room temperature and was larger in $\mathrm{CR} / \mathrm{A}$ than in HR samples.

Table 2. SFE values and grain sizes of 304L steel.

\begin{tabular}{cccc}
\hline 304L Steel & $\mathrm{SFE}\left(\mathrm{mL} / \mathrm{m}^{2}\right) 298 \mathrm{~K}$ & $\mathrm{SFE}\left(\mathrm{mL} / \mathrm{m}^{2}\right) 155 \mathrm{~K}$ & Average grain size $(\mu \mathrm{m})$ \\
\hline HR & 15.03 & 8.14 & 8.99 \\
CR/A & 14.76 & 7.87 & 9.37 \\
\hline
\end{tabular}
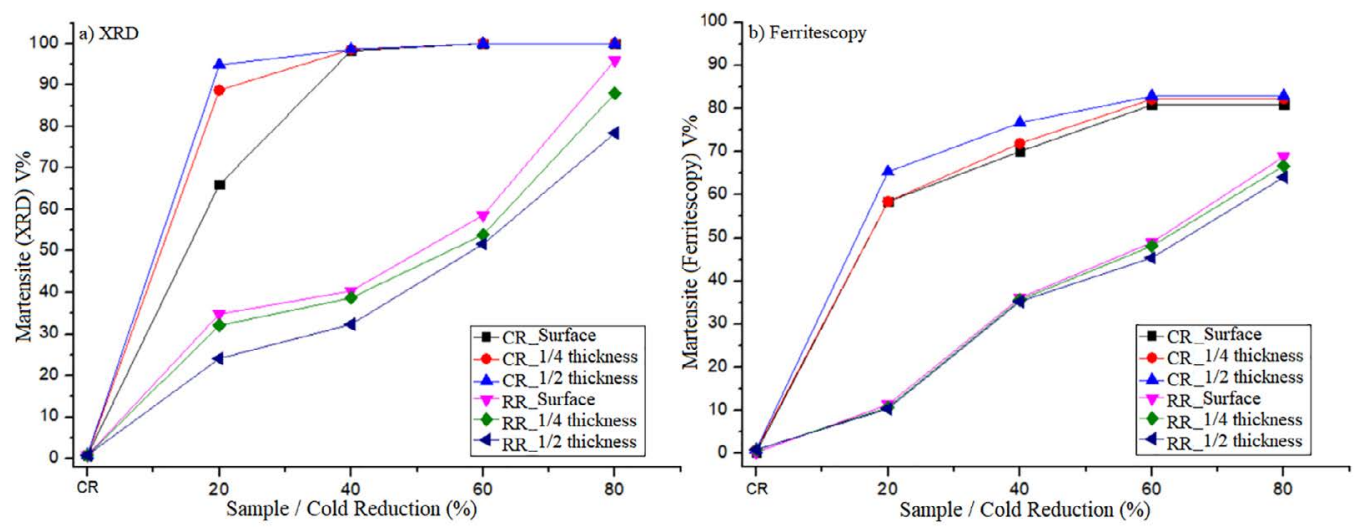

Figure 2. Induced martensitic transformation by rolling at $298 \mathrm{~K}(\mathrm{RR})$ and $155 \mathrm{~K}(\mathrm{CR})$. Analyses performed on whole, $3 / 4$ and $1 / 2$ samples.
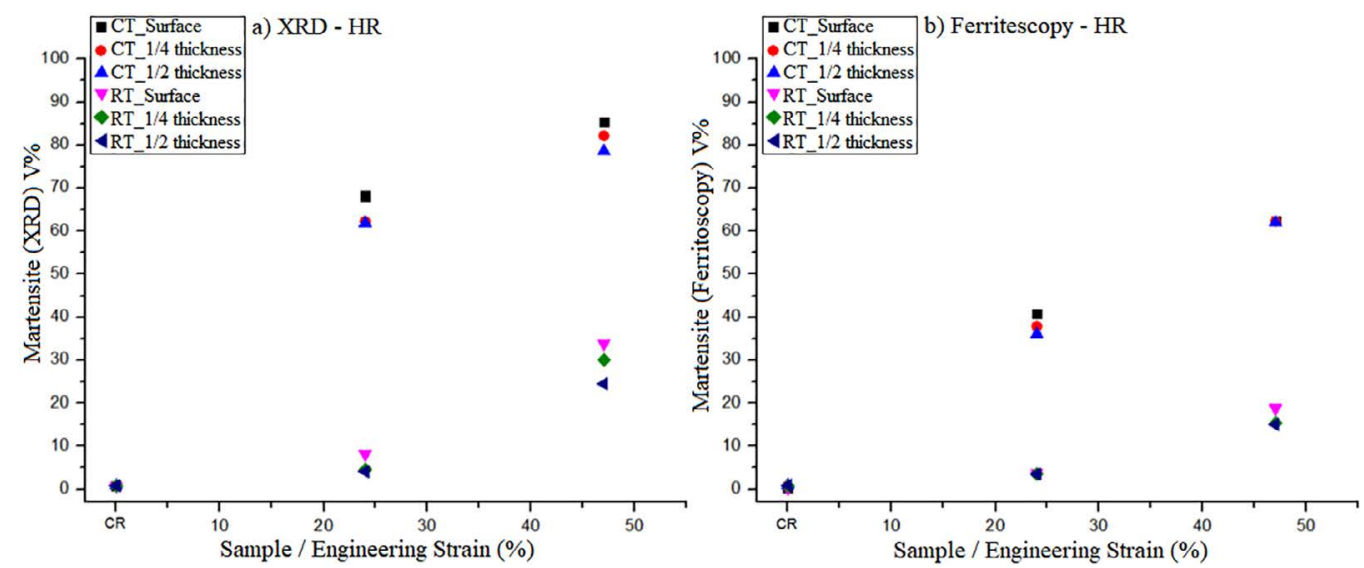

Figure 3. Induced martensitic transformation by tensile test at $298 \mathrm{~K}$ (RT) $155 \mathrm{~K}$ (CT) in HR samples. 

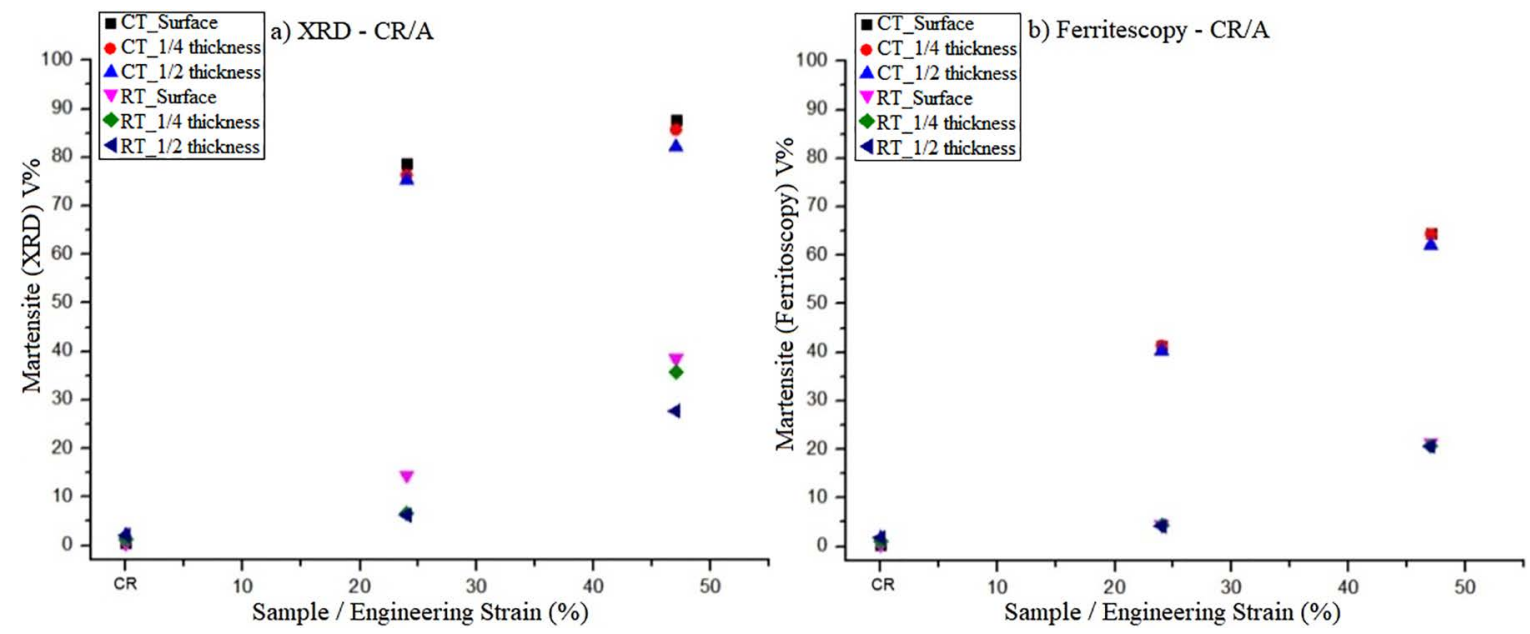

Figure 4. Induced martensitic transformation by tensile test at $298 \mathrm{~K}$ (RT) and $155 \mathrm{~K}$ (CT) in CR/A samples.

ANTUNES $^{9}$, SHIN $^{18}$ e MALLICK 5 reported that austenite instability is influenced by chemical composition, SFE and temperature. The chemical composition and induction temperature process affect directly the SFE and, therefore, also affect the martensitic transformation. As shown in Table 2, SFE was slightly larger for $\mathrm{HR}$ than for CR/A samples. The measured fractions of martensite are consistent with this result, in the sense that lower SFE values are associated with enhanced phase transformation because lead to the formation of stacking faults and shear bands that act as $\varepsilon$ and $\alpha^{\prime}$ martensite nucleation sites ${ }^{1-2,4,3,5}$.

As reported by OLSON ${ }^{19}$, when the material is supercooled to a temperature close to $M_{\mathrm{s}}$, stress-assisted martensite nucleation occurs between the $M_{s}$ e $M_{s \sigma}$ temperatures. As the strain increases, the energy supplied leads to the growth of martensite nuclei generated by stress. Based on the results, the thermomechanical processing to which the $304 \mathrm{~L}$ stainless steel was subjected (HR and CR/A) influenced the martensitic transformation by TRIP effect, as well, as the chemical composition of the material, SFE and temperature.

The martensitic transformation of the HR material induced by rolling, at room and cryogenic temperatures (RR and CR samples, respectively), and by uniaxial tensile deformation, at same temperatures (RT and CT samples), is presented in Figure 5.

As can be observed in Figure 5, at room and cryogenic temperatures, a larger volume of martensite was obtained by rolling than by tensile test. For example, after $47 \%$ deformation at $155 \mathrm{~K}$, a sample had $98 \%$ martensite when deformed by rolling and $85 \%$ when deformed by tensile test. After $24 \%$ deformation at room temperature, a sample had $35 \%$ martensite when deformed by rolling and $8 \%$ when deformed by tensile test. These differences are due to the different stress states acting in the deformation processes. According to SHIN ${ }^{18}$, martensite nucleation per unit volume is proportional to the internal energy of deformation and thus depends on the type of mechanical stress. FISHER and TURNBULL ${ }^{15}$

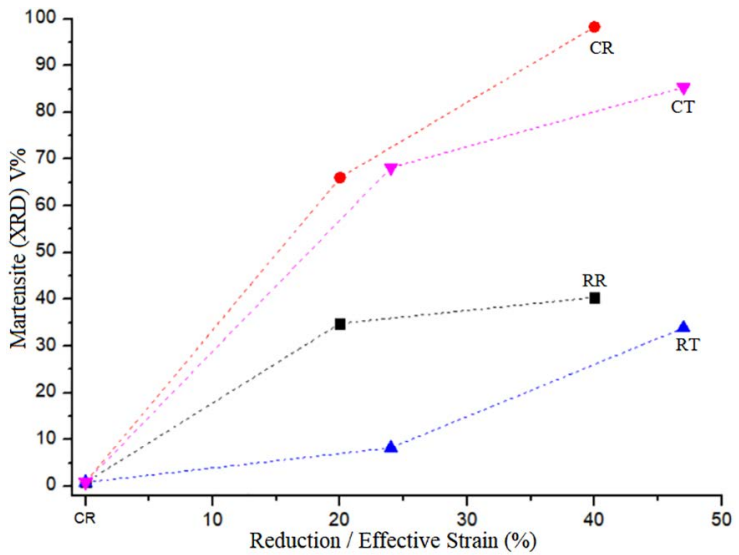

Figure 5. Induced martensitic transformation by rolling and tensile test at $298 \mathrm{~K}$ and $155 \mathrm{~K}$.

discussed the influence of traction and compressive stresses in relation to martensitic transformation, since the free energy difference associated with the volumetric expansion of this phase transformation is influenced by these stresses. Most of the volumetric expansion, austenite-martensite, occurs in a normal to the lenticular or habit planes and the work done for the normal stress per martensite volume unit is negative for compression. In general, the work involved in the martensitic transformation as well as the interface energy are influenced by the traction and compressive stresses and reflect $M_{s}$ temperatures. It can be noted from the results that the tension state had an important job on induced martensite transformation. STRINGFELLOW ${ }^{20}$ showed the stress state dependence in the kinetics of the induced martensite transformation by plasticity, which is faster for triaxial stress state, which is consistent with our data. Therefore, it can be observed that the stress triaxiality plays an important role on the strain-induced martensite transformation, which can be associate to higher martensite volume fraction observed in cold rolling samples. 
The presence of $\varepsilon$-martensite was observed in some samples and this was more relevant for the HR material. It was also observed that this phase was favored by the deformation mode, uniaxial tensile test, and lower deformation level.

The X-ray diffraction and ferritescope measurement techniques presented suitable results for the martensitic transformation analysis but cannot be directly compared unless it is assumed that the martensite phase is uniformly distributed over the sample. Moreover, these techniques measure different volumetric portions of the samples. Ferritescope measurement is a volume analysis that involves a larger volume of the material while the XRD measures a small surface layer.

\section{Conclusions}

The study of mechanically induced martensitic transformation in 304L austenitic stainless showed that the transformed fraction was larger in cold rolled and annealed (CR/A) samples than in hot rolled (HR) ones. This is attributed to the fact that (CR/A) samples have lower staking fault energy (SFE) than the hot rolled (HR) ones. It was also detected that the transformed fraction was higher in samples deformed by cold rolling than in samples deformed by tensile test, which can be associated to its triaxial stress state. The largest volume fraction of martensite, found in (CR/A) samples rolled at $155 \mathrm{~K}$, was $100 \%$ as measured by $\mathrm{XRD}$ and $80 \%$ as measured via ferritescope measurements, which corresponds to the detection limit of this technique. In general, the fraction transformed was smaller inside the samples than near the surface. This is attributed to heterogeneity of martensite nucleation.

\section{Acknowledgments}

The authors thank Aperam South America for supplying the material, FAPERJ for a Doctorate scholarship and $\mathrm{CNPq}$ for a research productivity grant (PQ-2), process 307798/2015-1.

\section{References}

1. Talonen J, Hänninen H. Formation of shear bands and strain-induced martensite during plastic deformation of metastable austenitic stainless steels. Acta Materialia. 2007;55(18):6108-6118.

2. Shen YF, Li XX, Sun X, Wang YD, Zuo L. Twinning and martensite in a 304 austenitic stainless steel. Materials Science and Engineering: A. 2012;552:514-522.

3. Okayasu M, Tomida S. Phase transformation system of austenitic stainless steels obtained by permanent compressive strain. Materials Science and Engineering: A. 2017;684(2017):712-725.

4. Huang JX, Ye XN, Xu Z. Effect of Cold Rolling on Microstructure and Mechanical Properties of AISI 301LN Metastable Austenitic Stainless Steels. Journal of Iron and Steel Research, International. 2012;19(10):59-63.
5. Mallick P, Tewary NK, Ghosh SK, Chattopadhyay PP. Effect of cryogenic deformation on microstructure and mechanical properties of 304 austenitic stainless steel. Materials Characterization. 2017;133:77-86.

6. Cina B. Effect of Cold Work on the $\gamma \rightarrow \alpha$ Transformation in Some Fe-Ni-Cr Alloys. Journal of the Iron and Steel Institute. 1954;177(8):406-422.

7. Angel T. Formation of Martensite in Austenitic Steels. Effects of Deformation, Temperature, and Composition. Journal of the Iron and Steel Institute. 1954;177(5):165-174.

8. Hedayati A, Najafizadeh A, Kermanpur A, Forouzan F. The effect of cold rolling regime on microstructure and mechanical properties of AISI 304L stainless steel. Journal of Materials Processing and Technology. 2010;210(8):1017-1022.

9. Antunes AEB, Antunes LMD, Sampaio M. Comportamento plástico no escoamento de aços inoxidáveis austeníticos metaestáveis. Revista Brasileira de Aplicações de Vácuo. 2011;30(1-2):18-23.

10. Prüger S, Seupel A, Kuna M. A thermomechanically coupled material model for TRIP-steel. International Journal of Plasticity. 2014;55:182-197.

11. Peng F, Dong XH, Liu K, Xie HY. Effects of Strain Rate and Plastic Work on Martensitic Transformation Kinetics of Austenitic Stainless Steel 304. Journal of Iron and Steel Research, International. 2015;22(10):931-936.

12. De AK, Murdock DC, Mataya MC, Speer JG, Matlock DK. Quantitative measurement of deformation-induced martensite in 304 stainless steel by X-ray diffraction. Scripta Materialia. 2004;50(12):1445-1449.

13. Helmut Fischer/Institut für Elektronik und Messtechnik. Operators Manual FERITSCOPE ${ }^{\circledR}$ FMP30. Determination the ferrite content of austenitic and DUPLEX stainless steel and determination of the ratio of martensite in austenitic stainless steels. Sindelfingen: Helmut Fischer/Institut für Elektronik und Messtechnik; 2008.

14. Helmut Fischer/Institut für Elektronik und Messtechnik. FERITSCOPE ${ }^{\circledR}$ FMP30 Measurement of the Ferrite Content in Austenitic and Duplex Steel. Sindelfingen: Helmut Fischer/ Institut für Elektronik und Messtechnik; 2012.

15. Fisher JC, Turnbull D. Influence of stress on martensite nucleation. Acta Metallurgica. 1953;1(3):310-314.

16. Egner H, Skoczeń B, Ryś M. Constitutive and numerical modeling of coupled dissipative phenomena in $316 \mathrm{~L}$ stainless steel at cryogenic temperatures. International Journal of Plasticity. 2015;64:113-133.

17. Nagy E, Mertinger V, Tranta F, Sólyom J. Deformation induced martensitic transformation in stainless steels. Materials Science and Engineering: A. 2004;378(1-2):308-313.

18. Shin HC, Ha TK, Chang YW. Kinetics of deformation induced martensitic transformation in a 304 stainless steel. Scripta Materialia. 2001;45(7):823-829.

19. Olson GB, Cohen M. A mechanism for the strain-induced nucleation of martensitic transformations. Journal of Less Common Metals. 1972;28(1):107-118.

20. Stringfellow RG, Parks DM, Olson GB. A constitutive model for transformation plasticity accompanying strain-induced martensitic transformations in metastable austenitic steels. Acta Metallurgica et Materialia. 1992;40(7):1703-1716. 